\title{
Is planet Earth as a whole likely to be wage-led?
}

\author{
Arslan Razmi* \\ Department of Economics, University of Massachusetts Amherst, USA
}

Open-economy considerations that create the possibility of 'beggar-thy-neighbor' effects offer one explanation for why the relationship between distribution, demand, and growth may be complicated in the short run. Several authors have argued recently, however, that even if demand and growth are profit-led in many individual countries, the global economy is likely to be wage-led since the planet as a whole runs balanced trade. This paper shows that this argument, while intuitively appealing, does not hold up to careful examination. Although the world economy as a whole is a closed system, it is not isomorphic to a closed economy, thanks to repercussion effects, relative price movements, and cross-country heterogeneity. Using asymmetries in consumption as a simple illustrative device I show that, in a two-country world, the effects of global redistribution depend on the nature of the constituent economies. This conclusion holds in spite of balanced trade at a planetary level, and regardless of whether one or both economies have excess capacity or whether zero-sum effects are present or not.

Keywords: demand regime, income distribution, wage-led growth, neo-Kaleckian openeconomy models

JEL codes: $F 43, O 41, O 11, E 12$

\section{INTRODUCTION AND BACKGROUND}

By recognizing the dual role of wages - as costs of production and sources of aggregate demand - neo-Kaleckian models have made an extremely important contribution to short-run macroeconomic analysis. In a closed-economy set-up with mark-up pricing, involuntary unemployment, unutilized capacity, and nominal wage stickiness, a redistribution of national income from capitalists to workers - who save less, on average - may generate additional spending and demand. If firms respond by increasing capacity utilization, output rises. Insofar as investment responds positively to expected future demand, higher utilization boosts accumulation given the profit share. Thus, growth in a closed demand-driven capitalist economy could be wageled barring a strong profit-share effect on desired investment. Other work, however, has shown that growth is much less likely to be wage-led in an open economy. This is because while redistribution towards workers boosts consumption demand, it

* Email: arazmi@econs.umass.edu. I would like to thank participants at the 2017 Annual Meetings of the Eastern Economic Association and the 2016 Conference of the FMM Research Network, in addition to the two anonymous referees for their helpful comments. 
simultaneously reduces external demand by making the domestic good less competitive in international markets.

Blecker (1989) investigated this issue in an open economy 'imperfect substitutes' framework by introducing a flexible mark-up factor over average variable costs. Depending on the specification of the mark-up, any increase in the real wage is partially or fully passed through to the export price, making domestic goods less competitive internationally. This counters any positive effects on growth through increased utilization and investment. Thus, if the Marshall-Lerner condition is satisfied, openeconomy considerations constrain the room for wage-led growth. Even an economy that is wage-led in the absence of international trade can transform into a profit-led one if a decline in real wages boosts international demand adequately to offset the fall in domestic absorption. However, this kind of growth has a 'beggar-thy-neighbor' aspect to it as it originates from one country 'stealing' demand from another. The rise in demand for the wage-lowering country, in other words, plays out in a zero-sum environment where one country benefits at the expense of the other. How is the analysis affected if we take the whole global economy as our unit of analysis?

Some recent literature has argued that since the world as a whole is a closed economy, global growth is likely to be wage-led. Put differently, since the constraint on export-led growth in an imperfect substitutes framework arises from the fact that one country runs trade surpluses at the expense of the other, and since the planet as a whole cannot run trade imbalances, the issues raised in an open-economy context are not relevant, and the global economy is highly likely to experience wage-led demand and growth. Lavoie and Hein (2015, p. 8) point out, for instance, that 'at the level of planet earth, since net exports are zero by definition, the only reasonable strategy for the expansion of aggregate demand is to pursue a strategy of wage-led growth, that is, a strategy that is favourable to the labour force.' Similarly, Onaran (2016, p. 464) observes that 'even if there are some countries that are profit-led, the global economy as a whole is wage-led because the world is a closed economy. This makes intuitive sense, because planet Earth is a closed economy - at least as long as we do not trade with Mars!'

It is not clear, however, that the conclusion follows from the premise. The relevant issue is the presence of trade imbalances within the planet, that is, between countries. As long as countries differ along the relevant dimensions (saving rates, levels of capacity utilization, resource scarcity, consumer behavior, etc.), global demand as a whole can be either wage-led or profit-led, even in the absence of beggar-thy-neighbor effects. The same observations apply with even greater force to global growth. The fact that the planet as a whole does not run trade surpluses or deficits against itself is not central.

To put the point across starkly, suppose that the world consists of two countries that are identical in size and every other aspect except that one country produces its own investment goods but imports all its consumption goods from the other country, whereas the other country is self-sufficient in consumption goods. Then a redistribution towards profits in the first country increases investment spending without affecting the (non-existent) consumer demand for the domestic good. Utilization rises as a result, and demand in that country is profit-led. Moreover, the boost in utilization increases consumer demand for the second country's goods, increasing utilization there as well. The world as a whole then appears to be profit-led thanks to differences in consumer demand for the goods produced in the two countries. Note that this happens in spite of the appearance of a trade surplus in one country and a trade deficit in the other. 
This paper explores the conditions under which the global economy as a whole could experience wage- or profit-led demand and growth in the short run. I start with a simple framework where the world consists of two countries and both countries are exactly identical in terms of the level of capital stocks, saving, investment and consumption behavior, and income distribution. Both countries are capital abundant in the sense that a lack of capital does not constrain production, and capacity utilization varies in response to demand. Employing this framework, I first show that, even in a zerosum, beggar-thy-neighbor world, the nature of world demand is not independent of constituent country characteristics. I do this by demonstrating the effects of relative price changes given distributional shares, and, in the presence of biases in consumption demand for goods produced in different countries. Next, I show that, even if we remove beggar-thy-neighbor effects by assuming constant relative prices, the nature of world demand and growth continues to depend on constituent country characteristics. Again, I do this by demonstrating the effects of biases in consumption patterns. In particular, I show that, even in this boiled-down set-up, global demand could be either profit-led or wage-led, while the nature of the demand regime within each country depends on global consumption behavior via repercussion effects. For example, if global consumption is skewed heavily towards the good produced by one country, then the other country will tend to have profit-led demand. The intuition is simple: if the good produced by a country is only used as an investment good, then any global redistribution towards profits necessarily increases demand for that good, regardless of the nature of the demand regime in the other country.

These simple exercises show that merely considering the global economy as a whole does not make wage-led growth more likely. The global economy is the sum of its parts. When divided into two equal parts, the planet as a whole is wage-led only if either: (i) both economies are wage-led, or (ii) if one economy is profit-led, the other economy is very strongly wage-led. Thus, as long as it is true that, as suggested by empirical studies, at least some countries have profit-led growth, one cannot make a general claim about the planet as a whole being wage-led.

Finally, I extend the model to reintroduce beggar-thy-neighbor effects by employing a more conventional structuralist North-South closure, with the South modeled as a capital-constrained economy with an exogenously fixed real wage. I show that the possibility of global wage-led growth is more limited in such a set-up. Intuitively, a global redistribution towards wages now lowers investment in the South without affecting capacity utilization, while possibly raising the latter in the North if it has wage-led demand.

In sum, the global economy can be either wage-led or profit-led. The fact that the globe as a whole has balanced trade is not the decisive factor one way or another.

To the best of my knowledge, one other paper has theoretically explored related issues in a two-country framework. ${ }^{1}$ Von Arnim et al. (2014) analyse the effects of redistribution in a country when it interacts with the rest of the world as a large economy. Analysing a two-country world with varying combinations of wage-led and growth-led economies, they show that redistribution in a country could raise global demand, even though it may lower relative growth for that country. The fact that one country

1. Onaran and Galanis (2012) investigate a sample of 16 G20 countries and find that growth in some is wage-led while in others it is profit-led. Their study is a purely empirical exercise, however, and focuses on simulating the effects of redistribution based on coefficients derived from individual countries. An analysis of the strengths and weaknesses of their empirical approach is beyond the scope of this paper. See Skott (2017) for a discussion. 
can derive benefits from redistribution in another country gives rise to a possible fallacy of composition. ${ }^{2}$ Due to the nature of their model, von Arnim et al. (2014) cannot explore the effects of differences between countries analytically and have to resort to numerical simulation. More importantly, the relevant thought exercise for our purposes would involve the global effects of redistribution across the world rather than in one country. This is because the argument that I explore in this paper is about whether the closed nature of the world as a whole makes wage-led growth more likely. Investigating this question requires analysing the comparative statics of redistribution that is global in nature. The analysis here, in other words, does not contradict or confirm that by von Arnim et al. (2014); rather, it addresses a different set of questions.

\section{A SIMPLE TWO-COUNTRY MODEL}

This section develops a two-country framework. It starts with the simplest case in Section 2.1, where both countries are exactly identical in terms of the level of capital stocks, saving, investment and consumption behavior, and income distribution, and, in Section 2.2, explores the (beggar-thy-neighbor) effects of relative price changes caused by nominal wage or exchange-rate changes. Only the (internationally identical) preference for one good or the other breaks the symmetry. The main conclusion is that, even in this boiled-down set-up, the nature of world demand and capital growth are not independent of constituent country characteristics. Next, Section 2.3 shows that, even if we eliminate beggar-thy-neighbor effects by assuming constant relative prices, the evolution of world demand and growth in response to distributional changes continues to depend on constituent country characteristics. Finally, Section 2.4 reintroduces relative price effects to show that earlier findings continue to apply in a more traditional structuralist set-up, where the North has varying capacity utilization while adjustment in the capital-scarce South takes place through relative price movements.

\subsection{When both countries are capacity-constrained}

Let's start by defining macroeconomic behavior. Consider two countries, say North and South, that are similar in the sense that neither economy has a capital constraint. Each produces a good - called good $N$ in the case of North and $S$ in the case of South and the two goods are imperfect substitutes in consumption. ${ }^{3}$ At this point I attach no significance to the terms North and South as far as income or structural differences are concerned. The terms are used, rather, as a device to distinguish two economies, both of which have excess capacity, and are characterized by rates of utilization (denoted by $u_{N}$ and $u_{S}$ ) that vary in order to equilibrate the respective goods markets. Section 2.4 will modify the analysis so that the nomenclature captures stylized differences between industrialized and developing economies in line with traditional usage.

Consumers in each country spend a fraction of their income on their own good and the remainder on the foreign good. Only profit income is saved. Utilization is proxied by outputs as ratios of capital stocks (for example, $u_{N} \equiv Y_{N} / K_{N}$ ). Thus, denoting the

2. See Palley (2003) and Blecker and Razmi (2008) for investigations of a fallacy of composition in the pursuit of export-led growth by developing countries.

3. See Table 1 for a list of symbols and their definitions. 
Table 1 Definitions of key variables

\begin{tabular}{ll}
\hline Variable & Definition \\
\hline$Y_{i}$ & Output of good $i$, respectively $(i=N, S)$ \\
$\pi_{i}$ & Profit share of output in each country $(i=N, S)$ \\
$C_{i j}$ & Consumption by country $j$ of good $i$ \\
$K_{i}$ & Stock of capital in country $i(i=N, S) ; k=K_{S} / K_{N}$ \\
$u_{i}$ & Capacity utilization rate in country $i$ \\
$\pi_{i}, \tau_{i}, W_{i}$ & Profit share of output, mark-up factor, and nominal wage in country $i$ \\
$I_{i}$ & Investment in country $i(i=N, S)$ \\
$T B$ & Trade balance \\
$S_{i}$ & Saving rate in country $i(i=N, S)$ \\
$P_{i}$ & Price of good $i$ \\
$q$ & Relative price $\left(\equiv P_{S} / P_{N}\right)$ \\
$\Theta_{i}$ & Share (with $q=1)$ of global consumption expenditure devoted to the good $i$ \\
\hline
\end{tabular}

consumption of good $i$ by country $j$ 's consumers by $C_{i j}$, I am able to define the following equations to describe macroeconomic consumption behavior after expressing all real variables in terms of the price of the $N$-good:

$$
\begin{gathered}
C_{N N}=\Theta_{N} q^{\gamma}\left(1-s_{N} \pi_{N}\right) u_{N} K_{N} \\
C_{S N}=\frac{\left(1-\Theta_{N} q^{\gamma}\right)\left(1-s_{N} \pi_{N}\right) u_{N} K_{N}}{q} \\
C_{S S}=\Theta_{S} q^{-\gamma}\left(1-s_{S} \pi_{S}\right) u_{S} K_{S} \\
C_{N S}=q\left(1-\Theta_{S} q^{-\gamma}\right)\left(1-s_{S} \pi_{S}\right) u_{S} K_{S} .
\end{gathered}
$$

The share of consumption of each $\operatorname{good}\left(\Theta_{N} q^{\gamma}\right.$ and $1-\Theta_{N} q^{\gamma}$ in the case of Northern consumers) is affected by its relative price $\left(q \equiv P_{S} / P_{N}\right) .{ }^{4}$ Ignoring government spending and taxes, we only need to define the investment functions in order to specify equilibrium conditions. Since I do not impose a trade balance condition, I can specify independent investment functions for each country. I employ general functions that specify investment as a function of profitability conditions and aggregate demand. ${ }^{5}$

$$
\begin{gathered}
\frac{I_{N}}{K_{N}}=f\left(\pi_{N}, u_{N}\right) \\
\frac{I_{S}}{K_{S}}=h\left(\pi_{S}, u_{S}\right)
\end{gathered}
$$

4. Notice that these shares can be fixed by simply assuming that $\gamma=0$.

5. The investment specifications here address the Marglin-Bhaduri critique of neo-Kaleckian investment functions (see Marglin and Bhaduri 1990). Modifying investment to be a function of the profit rate instead of the profit share will not qualitatively affect the gist of our analysis. 
The two goods market conditions in excess demand form follow:

$$
\begin{gathered}
C_{N N}+C_{N S}+\frac{I_{N}}{K_{N}}-u_{N}=0, \text { or } \\
N N\left(u_{N}, u_{S} ; \pi\right)=\left[\Theta_{N} q^{\gamma}\left(1-s_{N} \pi_{N}\right)-1\right] u_{N}+\left(1-\Theta_{S} q^{-\gamma}\right)\left(1-s_{S} \pi_{S}\right) q u_{S} k \\
+f\left(\pi_{N}, u_{N}\right)=0 \\
C_{S S}+C_{S N}+\frac{I_{S}}{K_{S}}-u_{S} k=0, \text { or } \\
S S\left(u_{N}, u_{S} ; \pi\right)=\left(1-\Theta_{N} q^{\gamma}\right)\left(1-s_{N} \pi_{N}\right) u_{N}+\left[\Theta_{S} q^{-\gamma}\left(1-s_{S} \pi_{S}\right)-1\right] q u_{S} k \\
+q h\left(\pi_{S}, u_{S}\right)=0,
\end{gathered}
$$

where all the quantities in both equations have been normalized by $P_{N} K_{N}$, and $k\left(\equiv K_{S} / K_{N}\right)$ defines the relative capital stock in the South.

\subsection{Beggar-thy-neighbor effects}

Before we explore the effects of redistribution on global income and demand, let's take a quick look at the consequences of a relative price change that leaves distribution unchanged. Does the world economy as a whole experience changes in demand as a result?

We can figure out the partial effect of a change in $q$ - keeping the distributional variables fixed - from equations (7) and (8). ${ }^{6}$

$$
\begin{gathered}
N N_{q}=\gamma \Theta_{N} q^{\gamma}\left(1-s_{N} \pi_{N}\right) u_{N}+\left[1-(1-\gamma)\left(1-\Theta_{S}\right) q^{-\gamma}\right]\left(1-s_{S} \pi_{S}\right) u_{S} k \\
S S_{q}=-\frac{\left[\gamma \Theta_{N}+\left(1-\Theta_{S}\right)\right] q^{\gamma}}{q^{2}}\left(1-s_{N} \pi_{N}\right) u_{N}-\left(1-\Theta_{S}\right) \gamma q^{-\gamma-1}\left(1-s_{S} \pi_{S}\right) u_{S} k
\end{gathered}
$$

An increase in $q$ substitutes demand away from the $S$-good and toward the $N$-good. To focus on the question at hand, let's now simplify by assuming that each country begins with the same level of capital stock ( $k=1$ initially) and that consumers in the two countries are exactly similar in that they have identical preferences over the basket of goods available. Thus, $\Theta_{N}=1-\Theta_{S}=\Theta$. In other words, consumers in both countries devote the same share of expenditure to each good. Let's assume also that wages, when measured in the same currency, are initially the same across countries, as is the constant mark-up over costs. This latter assumption translates into equal profit shares of income in each country $\left(\pi_{N}=\pi_{S}=\pi\right)$. Notice, also, that under these conditions, $q=1$. To see this, consider the relative price variable in more detail:

$$
q=\frac{\left(1+\tau_{S}\right) W_{S}}{\left(1+\tau_{N}\right) W_{N}}
$$

6. In the present framework, this means exploring the effects of a nominal change in the wage or the exchange rate. 
where $\tau_{i}$ and $W_{i}(i=N, S)$ represent the mark-up factors and nominal wages, respectively, and the nominal labor coefficients have been normalized to unity for simplicity. With full pass-through of labor costs into good prices, identical profit shares $\pi_{1} \equiv\left(\frac{\tau_{i}}{1+\tau_{i}}\right)$ require identical mark-up factors, so that $q=1$. Finally, let's assume away differences in saving and investment behavior in the two countries, so that $s_{N}=s_{S}=s, f_{\pi}=h_{\pi}$, and $f_{u}=h_{u}$.

In sum,

$$
\begin{gathered}
\Theta_{N}=1-\Theta_{S}=\Theta, \pi_{N}=\pi_{S}=\pi(\text { so that } q=1), s_{N}=s_{S}=s, f_{\pi}=h_{\pi} \\
f_{u}=h_{u}, \text { and initially, } W_{N}=W_{S}, k=1 .
\end{gathered}
$$

Now suppose there is a nominal devaluation in the North. The effect will be to raise $q$ (a real devaluation) without a change in distribution. In order to highlight the importance of country differences, we compare the cases where the countries are exactly identical in every respect with the one where they are not.

Consider first the case where the two countries are exactly identical in the sense that not only do the assumptions listed under (10) hold, but that, in addition, each country divides its consumption expenditure equally between the two goods (that is, $\Theta=0.5)$. In this case, the substitution towards the $N$-good caused by the Southern revaluation raises utilization in the North while lowering it to an identical extent in the South.

$$
\frac{d u_{N}}{d q}+\frac{d u_{S}}{d q}=\left(\frac{\gamma+0.5}{1-f_{u}}-\frac{\gamma+0.5}{1-f_{u}}\right)(1-s \pi) u_{N}=0
$$

The beggar-thy-neighbor effects cancel out between the two regions so that things play out at the global level as a zero-sum game. ${ }^{7}$ In such a world, relative price changes have an effect only at the country level. This is the case that one has in mind when one expects the world as a whole to act as a closed economy.

Next, consider the case where global consumption demand is extremely skewed towards the $S$-good, so that $\Theta=\Theta_{N}=0$ and $\Theta_{S}=1$. Unlike the previous case, this generates an asymmetry.

$$
\begin{aligned}
\frac{d u_{N}}{d q}+\frac{d u_{S}}{d q} & =\frac{(1-s \pi) \gamma u_{N}}{1-f_{u}}+\left[-\frac{\gamma\left(s \pi-f_{u}\right)+\left(1-f_{u}\right)}{\left(s \pi-f_{u}\right)\left(1-f_{u}\right)}(1-s \pi) \gamma u_{N}\right] \\
& =-\frac{1-s \pi}{s \pi-f_{u}} u_{N}<0
\end{aligned}
$$

The overall effect on utilization is negative even though substitution effects cancel out at the global level. Intuitively, this is because of the asymmetry in global consumption demand, as a result of which the negative valuation effect of the relative price change on Northern imports lowers global utilization.

Not surprisingly, the mirror-image result holds when global consumption demand is skewed towards the $N$-good (that is, $\Theta=\Theta_{N}=1-\Theta_{S}=0$ ).

7. Notice that the fact that the two countries are identical in terms of size allows us to add up the effects on the two rates of utilization to get the global effect. 


$$
\frac{d u_{N}}{d q}+\frac{d u_{S}}{d q}=\frac{1-s \pi}{s \pi-f_{u}} u_{N}>0
$$

Global consumption patterns matter. A bias towards consumption for any of the two goods leads to changes in global utilization in response to relative price changes. Unless its constituents are exactly identical, the world as a unit does not act like a closed economy. ${ }^{8}$

The difference considered here between the economies is that of global consumer preferences over the two goods. One would, of course, reach similar conclusions were one to explore other differences, such as those in saving rates, size, initial utilization rates, or distributional shares.

The next sections builds on the intuition derived here; I will continue to explore the effects of differences in global consumption of the two goods, but the thought experiments will now involve global distributional changes.

\subsection{Global redistribution toward wages}

Next, suppose there is a redistribution of income, globally, from profits to wages. In order to limit the number of moving parts, I will constrain the analysis to redistributions involving no changes in relative prices. ${ }^{9}$ That is, I will exclude the beggar-thy-neighbor effects of relative price changes. As demonstrated in Section 2.2, the main conclusion drawn from our exercise, that is, that the nature of world demand and growth is not independent of the constituent economies, is robust to relative price changes.

First, a look at the partial effects in each market:

$$
\begin{gathered}
-N N_{\pi}=\left[\Theta_{N} q^{\gamma} s_{N} u_{N}+\left(1-\Theta_{S} q^{-\gamma}\right) s_{S} u_{S} q k\right]-f_{\pi} \gtrless 0 \\
-S S_{\pi}=\left[\Theta_{S} q^{-\gamma} s_{S} u_{S} q k+\left(1-\Theta_{N} q^{\gamma}\right) s_{N} u_{N}\right]-h_{\pi} q k \gtrless 0 .
\end{gathered}
$$

Redistribution away from profits raises consumption spending in both countries. For either country, if this increase along with the boost to exports (due to repercussion effects) is sufficient to dominate the decline in investment due to the lower profit share, then demand in that country is wage-led; otherwise it is profit-led. The nature of demand is influenced by the initial distribution of world capital stock, global consumer preferences, and, of course, more standard factors such as saving and investment behavior. In order to anticipate later results, notice that the more world demand is skewed towards a country's own products, the more likely it is to have wage-led demand.

\subsubsection{Demand}

The world in this framework is essentially one large economy, except that there is a line running through it that divides it equally so that one good is produced in each part. In this world, one cannot have relative price effects from global redistribution

8. Notice, however, that substitution effects (as captured by the variable $\gamma$ ) are absent from the sums of global utilization rate changes regardless of the nature of constituent economies. This is the dimension in which the world does act as a closed economy.

9. Implicitly this requires that the proportional rise in the mark-up factor is identical in the two countries. 
since an identical change in the mark-up factor across the world will leave $q$ unchanged.

Under these conditions, and based on equations (7) and (8), we get the following expressions for comparative static changes in the rates of utilization following global redistribution towards wages:

$$
\begin{gathered}
-\frac{d u_{N}}{d \pi}=\frac{\left(1-f_{u}\right)\left[\Theta\left(u_{N}+u_{S}\right)-f_{\pi}\right]+(1-s \pi)(1-2 \Theta) f_{\pi}}{\left(s \pi-f_{u}\right)\left(1-f_{u}\right)} \gtrless 0 \\
-\frac{d u_{S}}{d \pi}=\frac{\left(1-f_{u}\right)\left[(1-\Theta) s\left(u_{N}+u_{S}\right)-f_{\pi}\right]-(1-s \pi)(1-2 \Theta) f_{\pi}}{\left(s \pi-f_{u}\right)\left(1-f_{u}\right)}
\end{gathered}
$$

Note that both bracketed terms in the denominators are positive by the traditional Keynesian stability conditions. ${ }^{10}$

Output in either economy could either be wage-led or profit-led. The outcome, as we shall see shortly, depends crucially on global consumption behavior in terms of composition. In order to dig deeper, let's explore some interesting cases.

\section{Skewed global preferences}

Consider first the case where global consumption demand is extremely skewed towards the $S$-good, so that $\Theta=\Theta_{N}=0$ and $\Theta_{S}=1$. The effect is to ensure that the North is profit-led. Why? Because, with the $N$-good being used only for investment, any redistribution towards wages leaves consumer demand for that good unchanged. The only remaining effect on demand is the negative one through lower investment demand. Mathematically,

$$
-\frac{d u_{N}}{d \pi}=-\frac{f_{\pi}}{\left(1-f_{u}\right)}<0
$$

The effect on the South, on the other hand, is ambiguous. The intuition is a bit more involved. Since global redistribution toward wages lowers utilization in the North, Southern exports suffer. The direct effect of the redistribution on demand for the $S$-good works through the two standard channels: (i) the direct effect on investment is to lower it, and (ii) the effect on consumption, and indirectly via consumption on demand, is positive. Thus, the overall effect on demand for the $S$-good is ambiguous.

$$
-\frac{d u_{S}}{d \pi}=\frac{\left(1-f_{u}\right) s\left(u_{N}+u_{S}\right)-\left(2-f_{u}-s \pi\right) f_{\pi}}{\left(s \pi-f_{u}\right)\left(1-f_{u}\right)} \gtrless 0
$$

It is clear, however, that the South is less likely to be wage-led than if it were a closed economy. This is because of the harm to exports that redistribution causes, even when beggar-thy-neighbor effects are absent by construction. To see this more

10. More specifically, stability requires that $s \pi>f_{u}$, while, given that $s, \pi<1$, we know that $s \pi<1$. 
clearly, we can decompose the numerator of the expression above into two terms, such that wage-led demand requires that:

$$
\left\{s\left[f_{u}\left(u_{N}+u_{S}\right)-f_{\pi} \pi\right]+\left(1-f_{u}\right) f_{\pi}\right\}-\left[s\left(u_{N}+u_{S}\right)-f_{\pi}\right]<0 .
$$

Now the second term (in square brackets) is positive if the South is wage-led, that is, $S S_{\pi}<0$, which tends to make the overall expression negative. However, the first term (in curly brackets) is highly likely to be positive, ${ }^{11}$ and makes satisfaction of the inequality less likely.

What about global demand?

$$
-\left(\frac{d u_{N}}{d \pi}+\frac{d u_{S}}{d \pi}\right)=\frac{s\left(u_{N}+u_{S}\right)-2 f_{\pi}}{\left(s \pi-f_{u}\right)} \gtrless 0
$$

A sufficient condition for global demand to be wage-led is that both countries be wage-led. Since that is not true in this case - recall that the North is unambiguously profit-led - the South should be sufficiently wage-led to offset the profit-led demand in the North. Mathematically this condition boils down to:

$$
s\left(u_{N}+u_{S}\right)-f_{\pi}>f_{\pi} .
$$

The left-hand side is the condition for the South to be profit- or wage-led (with the conditions summarized by equation (10) imposed on equation (12) and $\Theta=1$ ). Thus, if the South is profit-led, the globe as a whole is profit-led. If the South is wage-led, things become ambiguous in spite of the absence of beggar-thy-neighbor effects at the global level. ${ }^{12}$

Table 2 summarizes the results for ease of comparison between this and subsequent sections. Since the two countries are symmetric at this point, the same analysis would apply in mirror-image form if global consumer preferences were skewed towards the $S$-good rather than the $N$-good (that is, if $\Theta=1$ rather than 0.5 ).

11. Note that $f_{u}\left(u_{N}+u_{S}\right)$ is the response of investment to utilization in both countries, while $f_{\pi} \pi$ is the response to the profit share in the North only.

12. Note that, with $\Theta=0$, the trade balance conditions in the North and South are given by:

$$
T B_{N}=-(1-s \pi) u_{N}=-T B_{S} .
$$

Thus, the North starts out with a trade deficit while the South starts out with a surplus. Intuitively, the North buys all its consumer goods from the South. A redistribution towards wages has an ambiguous effect on the Northern trade balance, although it continues to have a trade deficit (and the South continues to have an equivalent trade surplus). Mathematically,

$$
-\frac{d\left(T B_{N}\right)}{d \pi}=-\frac{s\left(1-f_{u}\right) u_{N}-(1-s \pi) f_{\pi}}{1-f_{u}} \gtrless 0 .
$$

Why is the effect ambiguous? Intuitively, a redistribution toward wages increases consumption spending (hurting the trade balance) but also reduces $u_{N}$ (since the North is profit-led), which improves the trade balance. This remains a zero-sum world as far as the trade balance is concerned. 


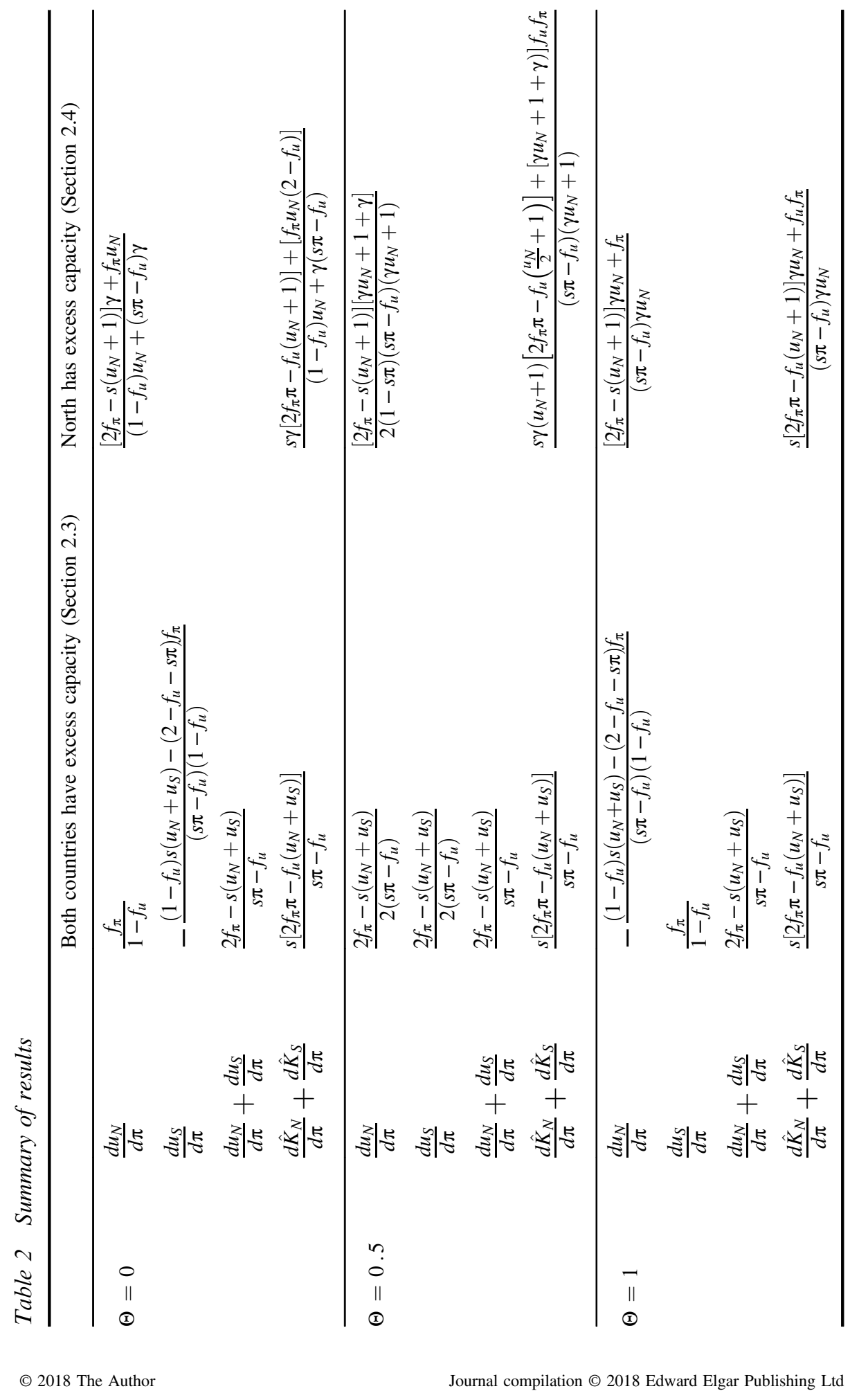




\section{Symmetric global preferences}

Next, consider the case where global consumers devote an equal proportion of their spending to either good, that is, $\Theta=\Theta_{N}=\Theta_{S}=0.5$. Now the relevant conditions assume a different form. Mathematically, from equations (13) and (14),

$$
-\frac{d u_{N}}{d \pi}=\frac{s\left(u_{N}+u_{S}\right)-2 f_{\pi}}{2\left(s \pi-f_{u}\right)}=-\frac{d u_{S}}{d \pi} \gtrless 0 .
$$

Not surprisingly, the condition for utilization to rise in response to global redistribution toward wages is the same in each country. Moreover, it is the same as the condition for global demand to be wage-led in the presence of skewed preferences (see equation (16) above). For the globe as a whole, the change in utilization is given by:

$$
-\left(\frac{d u_{N}}{d \pi}+\frac{d u_{S}}{d \pi}\right)=\frac{s\left(u_{N}+u_{S}\right)-2 f_{\pi}}{\left(s \pi-f_{u}\right)} \gtrless 0,
$$

which is the same as the condition in the case of skewed preferences. The necessary condition for both countries to be wage-led is that the globe be wage-led and a sufficient condition for the globe to be wage-led is that both countries be wage-led. As in the case of skewed preferences, if one of the two countries has profit-led demand, the world as a whole could have profit-led demand. Redistribution is not a zero-sum game at the global level.

\subsubsection{Growth}

Let's now turn our focus to the nature of effects on accumulation rather than demand in the short run and over time. Equations (5) and (6) have already defined investment behavior. Since the economies start with identical levels of capital stocks, the immediate change in the global rate of accumulation is given by $\frac{\hat{K}_{S}+\hat{K}_{N}}{2}$, where the hats over the variable symbols denote growth rates.

We are now in a position to revisit our thought experiment involving global redistribution. Once again, we will contrast scenarios with different global consumption behaviors.

\section{Skewed global preferences}

Recall that, in this case, the $N$-good is only used for investment $\left(\Theta=\Theta_{N}=0\right.$ and $\Theta_{S}=1$ ). Redistribution towards wages, therefore, lowers investment demand, making both demand and growth unambiguously profit-led in the North. Indeed, demand declines to the same extent as investment.

$$
-\frac{d \hat{K}_{N}}{d \pi}=-\frac{f_{\pi}}{\left(1-f_{u}\right)}<0
$$

As in the case of utilization, the effect on Southern accumulation is less clear. Indeed, not unexpectedly, the condition for wage-led growth is more stringent than that for wage-led demand. This is because, even if demand is wage-led, the resulting 
boost to investment must dominate the direct effect of a lower profit share on investment to make growth wage-led.

$$
-\frac{d \hat{K}_{S}}{d \pi}=-\frac{\left(1-f_{u}\right) s\left[f_{\pi} \pi-f_{u}\left(u_{N}+u_{S}\right)\right]+f_{u} f_{\pi}(1-s \pi)}{\left(s \pi-f_{u}\right)\left(1-f_{u}\right)} \gtrless 0
$$

A positive effect on global accumulation requires, as a sufficient condition, that investment in both countries be more sensitive to utilization than to the profit share (that is, $2 f_{\pi} \pi-f_{u}\left(u_{N}+u_{S}\right)<0$ ). Since growth in the North is unambiguously profitled, simply having wage-led growth in the other country will not suffice to make global accumulation wage-led. Instead, investment in the latter country will have to more than compensate for decumulation in the former country in response to redistribution.

$$
-\left(\frac{d \hat{K}_{N}}{d \pi}+\frac{d \hat{K}_{S}}{d \pi}\right)=-\frac{s\left[2 f_{\pi} \pi-f_{u}\left(u_{N}+u_{S}\right)\right]}{\left(s \pi-f_{u}\right)} \gtrless 0
$$

\section{Symmetric global preferences}

Recall that this is the case where consumers worldwide allocate an equal share of their consumption expenditures to each good $\left(\Theta=\Theta_{N}=0.5\right.$ and $\left.\Theta_{S}=0.5\right)$. In this case, both goods are demanded symmetrically so that neither of the two countries is unambiguously profit-led.

$$
-\frac{d \hat{K}_{S}}{d \pi}=-\frac{s\left[2 f_{\pi} \pi-f_{u}\left(u_{N}+u_{S}\right)\right]}{2\left(s \pi-f_{u}\right)}=-\frac{d \hat{K}_{N}}{d \pi} \gtrless 0
$$

The effect on investment in each country is determined by the cumulative effect in the two countries. A sufficient condition for global growth to be wage-led is that the utilization elasticity of investment in each country be less than the profit share elasticity. Exactly the same condition ensures that global growth is wage-led. A less stringent necessary condition is that at least one country have wage-led growth. If one of the countries has a profit-led growth regime, the other must have a strongly wage-led regime. The world as a whole may be either wage- or profit-led as long as the two countries differ in their regimes.

$$
-\left(\frac{d \hat{K}_{N}}{d \pi}+\frac{d \hat{K}_{S}}{d \pi}\right)=-\frac{s\left[2 f_{\pi} \pi-f_{u}\left(u_{N}+u_{S}\right)\right]}{\left(s \pi-f_{u}\right)} \gtrless 0
$$

\subsection{Extension: the traditional structuralist North-South closure}

Structuralist models have typically employed a different closure for North-South models whereby capacity utilization adjusts in response to disequilibria in the industrialized North while relative prices (or the terms of trade) adjust in a capacityconstrained South. ${ }^{13}$ As we see below, this closure makes global wage-led growth less likely. The two goods market equilibrium conditions are largely similar to what we had before (see equations (7) and (8)), with the difference that, with relative

13. See, for example, Taylor (1983, ch. 10), Blecker (1996), and Dutt (2002). 
price adjustment reintroduced, investment in the South is no longer a function of capacity utilization (which is normalized to unity for convenience). Assuming again that $\Theta_{N}=1-\Theta_{S}=\Theta$, and $s_{N}=s_{S}=s$, and $\pi_{N}=\pi_{S}=\pi$,

$$
\begin{aligned}
N N\left(u_{N}, q ; \pi\right)= & {\left[\Theta q^{\gamma}\left(1-s_{N} \pi\right)-1\right] u_{N}+\left[1-(1-\Theta) q^{-\gamma}\right](1-s \pi) q k } \\
& +f\left(\pi, u_{N}\right)=0 \\
S S\left(u_{N}, q ; \pi\right)= & \left(1-\Theta q^{\gamma}\right)\left(1-s_{N} \pi\right) u_{N}+\left[(1-\Theta) q^{-\gamma}(1-s \pi)-1\right] q k \\
& +h(\pi)=0 .
\end{aligned}
$$

Notice that, with full utilization, the profit share in the South is the same as the profit rate. Also, it may be useful to note that although output cannot be wage- or profit-led with full utilization, demand can, since only capitalists save.

We can now analyse our earlier distributional thought experiment employing the more traditional structuralist closure.

\subsubsection{Global redistribution again}

To carry out the analysis, we will have to separate movements in relative prices due to excess demand or supply in the goods markets from those due to policy-induced redistribution. Recall that, with exogenous profit shares in both regions, a redistribution towards wages requires a decline in the mark-up. Since the reduction in the mark-up factor is the same in both regions - our thought experiment involves identical redistribution across the world $-q$ is unchanged. When relative prices adjust, on the other hand, the real wages and profit shares must remain unchanged. In sum, distribution must remain exogenous, while endogenous relative price adjustments will now reintroduce the beggar-thy-neighbor expenditure-switching effects seen in Section 2.2. ${ }^{14}$

As earlier, first a look at the partial effects:

$$
\begin{gathered}
-N N_{\pi}=s \Theta\left(u_{N}+1\right)-f_{\pi} \gtrless 0 \\
-S S_{\pi}=s(1-\Theta)\left(u_{N}+1\right)-f_{\pi} \gtrless 0,
\end{gathered}
$$

where again $f_{\pi}=h_{\pi}$, and initially $k=q=1$. The partial effects are similar to those derived in the previous section - see equations (11) and (12) - except that now $u_{S}=1$, so that the sum of utilization rates appears in the expressions above as $u_{N}+1$ instead of $u_{N}+u_{S}$. Next, let's take a look at the comparative statics under different assumptions regarding consumer demand for the two goods.

\section{Global consumer preferences skewed towards the S-good}

Again, first the case where global consumption demand is extremely skewed towards the $S$-good, that is, $\Theta_{N}=0$ and $\Theta_{S}=1$, so that $\Theta=0$. In this case,

14. In mathematical terms, consider equation (9). Since the mark-up factor is an exogenous constant, changes in the price level must be reflected proportionally in the nominal wage or exchange rate, keeping the real wage constant. 


$$
\begin{gathered}
-\frac{d u_{N}}{d \pi}=-\frac{\left[2 f_{\pi}-s\left(u_{N}+1\right)\right] \gamma+f_{\pi} u_{N}}{\left(1-f_{u}\right) u_{N}+\left(s \pi-f_{u}\right) \gamma} \gtrless 0 \\
-\frac{d q}{d \pi}=-\frac{\left[2 f_{\pi}-s\left(u_{N}+1\right)\right]-s\left[f_{\pi} \pi-f_{u}\left(u_{N}+1\right)\right]-f_{u} f_{\pi}}{\left[\left(1-f_{u}\right) u_{N}+\left(s \pi-f_{u}\right) \gamma\right](1-s \pi)} \gtrless 0 .
\end{gathered}
$$

Recall that, in Section 2.3, where both regions had excess capacity, demand was unambiguously profit-led in this scenario. The reason was that, with no consumption of the Northern good, any reduction in the profit share will result only in lower investment demand. Now things are more ambiguous. Even though no Northern goods are initially being demanded for consumption, the redistribution may lead to a rise in the equilibrium value of $q$ if demand in the South is wage-led, which would in turn cause a consumption switch towards Northern goods. Notice that, in the absence of expenditureswitching effects, that is, with $\gamma=0$,

$$
-\frac{d u_{N}}{d \pi}=-\frac{f_{\pi}}{1-f_{u}}<0
$$

which is unambiguously signed and is in fact the expression that we got earlier when both regions had excess capacity (see equation (15)). Obviously the effect of removing expenditure-switching effects is to ensure that the level of output in the North is profit-led.

\section{Symmetric global preferences}

Next, consider the case where $\Theta_{N}=\Theta_{S}=\Theta=0.5$. The sufficient but not necessary condition for $u_{N}$ to be higher in the new equilibrium after a redistribution toward wages is that demand in both countries be wage-led, that is, the decline in investment following redistribution be higher than that in saving in each country. The same condition is sufficient to ensure a decline in Southern terms of trade $(q)$. Mathematically,

$$
\begin{gathered}
-\frac{d u_{N}}{d \pi}=\frac{\left[s\left(u_{N}+1\right)-2 f_{\pi}\right]\left[\gamma u_{N}+1+\gamma\right]}{2(1-s \pi)\left(s \pi-f_{u}\right)\left(\gamma u_{N}+1\right)} \gtrless 0 \\
-\frac{d q}{d \pi}=\frac{\left[s\left(u_{N}+1\right)-2 f_{\pi}\right]\left(1-f_{u}\right)}{2(1-s \pi)\left(s \pi-f_{u}\right)\left(\gamma u_{N}+1\right)} \gtrless 0 .
\end{gathered}
$$

Again, notice that, if $\gamma=0-$ that is, there are no expenditure-switching/beggarthy-neighbor effects - the condition for global output and demand to be demand-led (that is, $d u_{N} / d \pi>0$ ) reduces to that in the case where both regions had excess capacity (see equation (18)).

\section{Global consumer preferences skewed towards the N-good}

Now the case where $\Theta_{N}=1, \Theta_{S}=0$, so that $\Theta=1$. Only the Northern good is used for consumption across the world. Recall that we did not have to consider this case in Section 2.3 since utilization there adjusted in both countries, making these mirror 
images of each other in every dimension except for consumption demand for their goods. In the present case, redistribution toward wages unambiguously lowers investment demand for the $S$-good, which in turn reduces $q$, leading to substitution away from the Northern good. Demand for the Northern good depends on this effect in addition to the standard one that depends on whether the world demand as a whole is wageled or profit-led. The weaker the substitution effect (as measured by $\gamma$ ), the greater the decline in $q$, and as a result, the higher the likelihood that world demand as a whole is profit-led.

$$
\begin{gathered}
-\frac{d u_{N}}{d \pi}=\frac{\left[s\left(u_{N}+1\right)-2 f_{\pi}\right] \gamma u_{N}-f_{\pi}}{\left(s \pi-f_{u}\right) \gamma u_{N}} \gtrless 0 \\
-\frac{d q}{d \pi}=-\frac{f_{\pi}}{(1-s \pi) \gamma u_{N}}<0
\end{gathered}
$$

\subsubsection{Growth}

How is growth (as opposed to demand) affected by redistribution in this case, where the South has full capacity utilization? Since it is global growth that we are interested in, let's take a look at the expressions for aggregated global growth. Since growth in the South is now only a function of the profit rate (share), intuitively one would expect the likelihood of global wage-led growth to be lower in this case. This is indeed the main outcome of the analysis below.

\section{Global consumer preferences skewed towards the S-good}

Recall that, in the case where global preferences are skewed, so that $\Theta=0$, the sufficient condition for global growth to be wage-led was that growth in both countries be wage-led. This is no longer sufficient. Now the condition for wage-led global growth is more stringent, and is given by:

$$
-\left(\frac{d \hat{K}_{N}}{d \pi}+\frac{d \hat{K}_{S}}{d \pi}\right)=-\frac{s \gamma\left[2 f_{\pi} \pi-f_{u}\left(u_{N}+1\right)\right]+\left[f_{\pi} u_{N}\left(2-f_{u}\right)\right]}{\left(1-f_{u}\right) u_{N}+\gamma\left(s \pi-f_{u}\right)} .
$$

The term in the first set of square brackets in the numerator is the same as in the case where both regions had excess capacity (see equation (19)). The second pair of square brackets in the denominator contain the additional positive term that makes wage-led growth less likely even if investment is more responsive to the profit share than to utilization.

\section{Symmetric global preferences}

With symmetric global preferences, that is, $\Theta=0.5$, again the sufficient condition for global growth to be wage-led is more stringent compared to the case where both regions have excess capacity. This is captured by the additional term $\left.\left[1+\gamma+\gamma u_{N}\right)\right] f_{u} f_{\pi}$ in the numerator below.

$$
-\left(\frac{d \hat{K}_{N}}{d \pi}+\frac{d \hat{K}_{S}}{d \pi}\right)=-\frac{\left.s \gamma\left(u_{N}+1\right)\left[2 f_{\pi} \pi-f_{u}\left(\frac{u_{N}}{2}+1\right)\right]+\left[\gamma u_{N}+1+\gamma\right)\right] f_{u} f_{\pi}}{\left(s \pi-f_{u}\right)\left(\gamma u_{N}+1\right)}
$$




\section{Global consumer preferences skewed towards the N-good}

The expression derived in this case, that is, when $\Theta=1$, is as follows:

$$
-\left(\frac{d \hat{K}_{N}}{d \pi}+\frac{d \hat{K}_{S}}{d \pi}\right)=-\frac{s\left[2 f_{\pi} \pi-f_{u}\left(u_{N}+1\right)\right] \gamma u_{N}+f_{u} f_{\pi}}{\left(s \pi-f_{u}\right) \gamma u_{N}} .
$$

Unlike the case where both regions had excess capacity, it is no longer enough for both countries to be wage-led to make global growth wage-led. Instead, the additional term $f_{u} f_{\pi}$ that appears in the numerator means that the world as a whole experiencing wage-led growth is less likely in this case.

In sum, in all three cases considered, world growth is less likely to be wage-led when one country is capacity-constrained.

\section{CONCLUDING REMARKS}

Do open-economy arguments pointing out the constraints to wage-led demand and capital growth become irrelevant once we consider the fact that the planet as a whole is a closed system? This paper zooms in on differences in consumption demand to illustrate that this is not the case. Even in a closed world economy, where both countries have excess capacity and underutilized resources, the world as a whole could easily be profit-led. This is because, as long as there is a line dividing the world into two countries that produce different goods, only one country needs to be profitled in order for the world as a whole to be profit-led. The fact that global consumption of the two goods is not identical may indeed push demand regimes in some countries in the direction of being profit-led.

The lesson extends to a multi-country world, where again it's possible at least in theory for world demand and growth to be profit-led if even one or a few countries have that feature. Furthermore, the likelihood of world growth being profit-led increases if one incorporates the typical structuralist assumption that the South is capitalconstrained, or that the Southern countries are price-takers in international tradable markets. ${ }^{15}$ That the world economy is a closed system is not the central issue as long as individual countries have trade imbalances, repercuss, and/or are not exactly alike in all respects.

\section{REFERENCES}

Blecker, R. (1989), 'International competition, income distribution, and economic growth,' Cambridge Journal of Economics, 13, 395-412.

Blecker, Robert (1996), 'The new economic integration: structuralist models of North-South trade and investment liberalization,' Structural Change and Economic Dynamics, 7, 321-345.

Blecker, Robert and A. Razmi (2008), 'The fallacy of composition and contractionary devaluations: output effects of real exchange rate shocks in semi-industrialised countries,' Cambridge Journal of Economics, 32(1), 83-109.

Dutt, A.K. (2002), 'Thirlwall's law and uneven development,' Journal of Post Keynesian Economics, 24(3), 367-390.

15. See, for example, Ros (2016) and Razmi (2015; 2016). 
Lavoie, Marc and Eckhard Hein (2015), 'Going from a low to a high employment equilibrium,' Working Paper 144, Düsseldorf: Macroeconomic Policy Institute.

Marglin, Stephen and Amit Bhaduri (1990), 'Profit squeeze and Keynesian theory,' in S. Marglin and J. Schor (eds), The Golden Age of Capitalism, Oxford: Oxford University Press, pp. 153-186.

Onaran, Ozlem (2016), 'Wage- versus profit-led growth in the context of globalization and public spending: the political aspects of wage-led recovery,' Review of Keynesian Economics, 4(4), 458-474.

Onaran, O. and G. Galanis (2012), 'Is aggregate demand wage-led or profit-led? National and global effects,' Conditions of Work and Employment Series 40, Geneva: International Labour Office.

Palley, Thomas (2003), 'Export-led growth: evidence of developing country crowding-out,' in P. Arestis, M. Baddeley, and J. McCombie (eds), Globalization, Regionalism, and Economic Activity, Cheltenham, UK and Northampton, MA: Edward Elgar Publishing, pp. 175-197.

Razmi, Arslan (2015), 'The limits to wage-led growth in a low-income economy,' Metroeconomica, 66(4), 740-770.

Razmi, Arslan (2016), 'Growth and distribution in low-income economies: modifying postKeynesian analysis in light of theory and history,' Review of Keynesian Economics, 4(4), 429-449.

Ros, Jaime (2016), 'Can growth be wage-led in small open developing economies?' Review of Keynesian Economics, 4(4), 450-457.

Skott, Peter (2017), 'Weaknesses of "wage-led growth", Review of Keynesian Economics, 5(3), 336-359.

Taylor, Lance (1983), Structural Macroeconomics: Applicable Models for the Third World, New York: Basic Books.

Von Arnim, Rudiger, Daniele Tavani, and Laura Carvalho (2014), 'Re-distribution in a neoKaleckian two-country model,' Metroeconomica, 65(3), 430-459. 